\title{
Effect of the insect feeding deterrent 1-allyloxy-4- propoxybenzene on olfactory responses and host choice of Varroa destructor
}

\author{
Nitin K. SINGH ${ }^{1}$, Nurit ELIASH ${ }^{1}$, Starlin RAJ ${ }^{1}$, Jeongmee KIM ${ }^{2}$, Yang YU ${ }^{2}$, \\ Erika PLETTNER $^{2}$, Victoria SOROKER ${ }^{1}$ \\ ${ }^{1}$ Institute of Plant Protection, Agricultural Research Organization, The Volcani Center, PO Box 15159, 7505101, Rishon \\ LeZion, Israel \\ ${ }^{2}$ Department of Chemistry, Simon Fraser University, 8888 Univ. Dr., Burnaby, B.C. V5A 1S6, Canada
}

Received 10 October 2019 - Revised 15 May 2020 - Accepted 21 July 2020

\begin{abstract}
The ectoparasitic mite, Varroa destructor Anderson and Trueman (Acar: Varroidae), is a major threat for the honey bee, Apis mellifera L. Varroa behavior and physiology are influenced by compounds produced by the honey bee, as well as cues from the general colony environment. As part of our effort to disrupt varroa host chemosensing, we tested 1-allyloxy-4-propoxybenzene, 3c $\{3,6\}$, a known feeding deterrent of Lepidoptera larvae and a repellent of mosquitoes of similar activity to DEET. Its effect on varroa mites was evaluated by electrophysiological and behavioral bioassays. Its effect on honey bee chemosensing was also assessed. Compound $\mathbf{3 c}\{3,6\}$ is sensed by honey bees, but the detection of the compound alone by varroa is not clear. The electrophysiological study showed that 3c $\{3,6\}$ decreases the varroa foreleg responses towards head space odor of nurse bees. However, the response of honey bee antennae towards nurse bee head space odor was not affected. Consistent with electrophysiological studies, in the presence of $\mathbf{3 c}\{3,6\}$, the ability of varroa to reach any host decreased at the end of the experiment. No lethal effect to the honey bees was recorded. These data showed that $\mathbf{3 c}\{3,6\}$ affects the peripheral olfactory system of varroa by disrupting the chemical recognition process.
\end{abstract}

invertebrate chemoreception / host detection / olfaction / dialkoxybenzene / host choice

\section{INTRODUCTION}

The ectoparasitic mite Varroa destructor (Anderson and Trueman) is at the top of the list of risk factors for honey bee colony losses. This mite parasite of honey bees originally developed in association with the Eastern honey bee, Apis cerana (Rosenkranz et al. 2010), but since the beginning of the last century, mites are spreading worldwide among the colonies of the European

Corresponding author: E. Plettner, plettner@sfu.ca; V. Soroker, sorokerv@ volcani.agri.gov.il

Manuscript editor: Peter Rosenkranz honey bee $A$. mellifera, vectoring highly pathogenic viruses (Francis et al. 2013; Kuster et al. 2014).

Failure of conventional chemical acaricides in varroa control is triggered by resistance (Martin 2004; González-Cabrera et al. 2013) which then necessitates the use of higher doses of the agent to achieve mite control. Higher doses, in turn, can lead to sublethal effects on the bees (e.g., Mondet et al. 2011; Hillier et al. 2013; Frost et al. 2013; Berry et al. 2013). Both resistance and negative effects of widely used acaricides on bees are driving the search for new, more environmentally sustainable methods of varroa control. In an effort to develop new approaches to varroa control, we aim to disrupt its association with the honey bee. 
The life cycle of varroa is totally dependent on that of its host, the honey bee, and is divided into the following two stages: non-reproductive (previously called phoretic) and reproductive (reviewed by Rosenkranz et al. 2010; Nazzi and Le Conte 2015). Briefly, in the non-reproductive stage, mites tend to attach to adult bees and feed on their fat body (Ramsey et al. 2019) and hemolymph (Cabrera et al. 2017), whereas in the reproductive stage, mites reproduce within the capped brood cells feeding on pupal tissues. Nonreproductive varroa can also move freely on the surface of the comb in search of new hosts.

Laboratory bioassays by several researchers proved that varroa mites are using chemical cues for discriminating between bees from different task groups and to prefer a nurse over a forager bee (Nazzi et al. 2001; Pernal et al. 2005; Eliash et al. 2014). These cues are apparently detected by a chemosensory organ localized on the mites' forelegs. At the same time, colonial activities of honey bees are also coordinated mainly by chemical cues detected by their antennae. Electrophysiology was shown to be a reliable technique for identification of chemosensory disrupting compounds for Varroa (Eliash 2012; Eliash et al. 2014; Singh et al. 2015). Using this technique, we have screened 13 chemicals, including dialkoxybenzenes and ethers of 5(2'hydroxyethyl) cyclopent-2-en-1-ol (cy ethers) and the widely used insect repellent, N,Ndiethyl-meta -toluamide (DEET). The most active compounds found in that screen disrupted host selection by varroa mites, but their mode of action was different. While dialkoxybenzene and cy ethers switched the preference of varroa mites towards foragers without affecting the ability of the mites to reach a bee, DEET specifically reduced the ability of mites to reach a bee without affecting the preference. Moreover, DEET was not found to affect chemosensing and behavior of honey bees. This specificity and efficacy of DEET made it an attractive candidate for varroa control. However, negative effects of DEET are also well known and, in particular, it inhibits the activity of a key central nervous system enzyme, acetylcholinesterase, in both insects and mammals (Corbel et al. 2009).
Compound 3c $\{3,6\}, 1-$ allyloxy-4propoxybenzene, was first discovered as part of a screen of a dialkoxybenzene library for larval feeding deterrence against Trichoplusia $n i$ (Akhtar et al. 2010). Compound 3c $\{3,6\}$ was the larval feeding deterrent with the lowest $\mathrm{DC}_{50}$ value. Later, it was discovered that this compound can synergize with the active deterrent in neem, Azadirachtin A, with regard to larval feeding deterrence of T. ni (Cameron et al. 2014). Recently, it was found that compound $\mathbf{3 c}\{3,6\}$ repels malaria mosquitoes (Anopheles gambiae) with similar efficiency than DEET (Hodson et al. 2016). Therefore, we decided to test this compound against varroa.

\section{MATERIALS AND METHODS}

\subsection{Biological materials}

The experimental apiary was maintained at ARO (Volcani Center, Bet Dagan, Israel). All the bee colonies were kept in standard wooden "Langstroth" hives fitted with a screen bottom board. The hives were maintained without any treatment against varroa and received seasonal sugar feed. The source colony for the toxicological experiment with bees was maintained, in the same manner, in Port Moody, B. C., Canada.

\subsection{Varroa collection}

Female adult varroa mites were collected directly from emerging bees or walking on the combs, using fine tweezers and a fine paint brush. All collected varroa were kept on a moistened filter paper at room temperature until use or not more than $3 \mathrm{~h}$.

\subsection{Honey bee collection}

Nurse and forager bees were collected for the experiments. Bees observed leaning into brood cells were regarded as nurse bees, whereas pollen foragers carrying pollen loads were collected from the entrance of the hive according to Eliash et al. (2014). The bees were killed by freezing at $20^{\circ} \mathrm{C}$ for $1 \mathrm{~h}$. Prior to a behavioral bioassay, the pollen loads were removed from forager bees by 
using forceps or a paint brush under a stereo microscope.

Bees for the toxicological experiment were collected from a brood comb into a collection jar. For exposure by feeding at SFU, freshly collected bees were anesthetized in the laboratory with a stream of nitrogen, and then distributed into Plexiglass hoarding cages $(10.5 \times 12.0 \times 8.0 \mathrm{~cm}, \mathrm{H} \times \mathrm{W} \times \mathrm{D})$ using soft tweezers. For exposure to compounds in the gas phase at ARO, bees were collected similarly but were anesthetized by cooling before transfer into hoarding cages. In all cases, the bees did not have any mites.

\subsection{Chemicals}

Compound 3c $\{3,6\}, 1-$ allyloxy-4propoxybenzene, was available from previous synthetic lots, prepared from 1,4-dihydroquinone as described previously (Paduraru et al. 2008). All chemicals were of the highest available grade, and the product was checked by nuclear magnetic resonance and gas-chromatography-mass spectrometry and found to be pure. Briefly, 1,4dihydroquinone was treated with 2 equivalents of solid $\mathrm{K}_{2} \mathrm{CO}_{3}$ in spectro-grade acetone and reacted with 1 equivalent of allyl bromide for $12 \mathrm{~h}$ at room temperature. The product was vacuum filtered, to remove the potassium carbonate solids, and then the solvent was largely removed by rotary evaporation. The resulting sludge was brought up in saturated $\mathrm{NH}_{4} \mathrm{Cl}$ and extracted with ethyl acetate three times. The ethyl acetate extract was concentrated by rotary evaporation. The resulting product contained both 4allyloxyphenol and 1,4-diallyloxybenzene (3c $\{6,6\})$, which were separated by flash column chromatography using hexane/ethyl acetate as solvent, in a gradient from $10 \%$ ethyl acetate to $20 \%$ ethyl acetate. Batches were prepared on a scale of $\sim 1 \mathrm{~mol}$ (110 g) of dihydroquinone starting material. Typical yields were $\sim 37 \mathrm{~g}$ of 4-allyloxyphenol, $\sim 29$ g of 4-allyloxyphenol mixed with $3 \mathbf{c}\{6,6\}$, and $\sim 46 \mathrm{~g}$ of pure 3c $\{6,6\}$. The 4-allyloxyphenol is the compound we required for the next step in the synthesis of compound $\mathbf{3 c}\{3,6\}$.

The 4-allyloxyphenol was alkylated with 1bromopropane in spectro-grade acetone using
$\mathrm{K}_{2} \mathrm{CO}_{3}$ as the base, with gentle reflux. The alkylation reaction was run for $24 \mathrm{~h}$. Product was isolated by filtration and washing of the sediment with hexane. The pooled organic layers were concentrated by evaporation on a rotary evaporator. The product was a light yellow solid. A reaction started with $81 \mathrm{~g}$ of 4-allyloxyphenol yielded $91 \mathrm{~g}$ of crude product. The crude product was purified on a column of silica gel, using $3 \%$ ethyl acetate in hexane as the solvent, giving $86 \mathrm{~g}$ of $\mathbf{3 c}\{3,6\}$.

\subsection{Electrophysiological assays}

In the electrophysiological assays, varroa forelegs or bee antennae were used. The organs were stimulated by puffs of nurse honey bee odor or clean air (control) as explained in detail by Singh et al. (2015). Briefly, once a foreleg or bee antenna preparation was found responsive to a positive stimulus, the tested chemical was blown over the leg/antenna with or without positive stimuli. Headspace of five nurse bee was used as a positive stimulus. These stimuli were selected for varroa following Eliash et al. (2014) and following dose response tests on nurse antennae challenged with headspace of 1,5 , and 10 nurse or forager bees (this study). Electrophysiological responses of isolated varroa foreleg and bee antennae were recorded using Synthech equipment, and the order of stimuli was as explained in detail in our previous work (Singh et al. 2015). The response amplitude was recorded for each stimulus and normalized relative to air as described in our previous publication (Eliash et al. 2014).

\subsection{Choice bioassay}

Functional activity of the compound was performed using choice bioassay in glass Petri dishes, as described previously (Singh et al. 2015). Briefly, in the presence of the synthetic compound or solvent as a control presented on a piece of Parafilm $(\sim 2 \times 2 \mathrm{~cm})$ attached to the lid of the dish, a mite was given a choice of two bees (a forager and a nurse, both freshly freeze-killed) in a Petri dish (glass with $90 \mathrm{~mm}$ in diameter and $17 \mathrm{~mm}$ in depth). The location of the mite and its host preference was monitored at every hour for $3 \mathrm{~h}$. 


\subsection{Effect of compound $3 \mathrm{c}\{3,6\}$ on bees}

\subsubsection{Exposure of bees to the compound on parafilm}

The test was conducted on twenty freshly collected bees. Bees maintained in the classic hoarding cages as described by Medrzycki et al. (2013). The bees were provided with water and honey bee candy (a mix of sucrose powder and honey (1:2) ad libitum). The experiments were conducted in ten replicates. The dose of $\mathbf{3 c}\{3,6\}$ was $300 \mu \mathrm{g}$ in $30 \mu \mathrm{L}$ of hexane or $30 \mu \mathrm{L}$ of pure hexane (control) was placed on parafilm $(5 \times 5 \mathrm{~cm})$. After the hexane had evaporated, the parafilm release devices were introduced to cages and the cages were placed into incubators. The experimental and control cages were kept in separate incubators at $\left(28-30^{\circ} \mathrm{C}\right)$ and $\mathrm{RH}(50-70 \%)$, and bee mortality rate was recorded at 24,48 , and $72 \mathrm{~h}$.

\subsubsection{Exposure of bees to the compound in sugar syrup}

Bees were kept in Plexiglass cages with access to water and sugar syrup (made with water 1:1). The latter contained $32 \mathrm{mM}$ or $1.0 \mathrm{mM}$ of $3 \mathbf{c}\{3,6\}$ in sugar syrup. To dissolve the compound $3 \mathbf{c}\{3,6\}$ in the sugar syrup, 61.4 or $1.92 \mathrm{mg}$ of $3 \mathbf{c}\{3,6\}$ was first dissolved in $200 \mu \mathrm{L}$ of isopropanol, and then, this solution was added into $10 \mathrm{~mL}$ of sugar syrup. In the $32 \mathrm{mM}$ treatment, the compound $\mathbf{3 c}\{3,6\}$ formed some small crystals which floated in the syrup. This was not observed in the $1.0 \mathrm{mM}$ treatment. The control was sugar syrup with $2 \%(v / v)$ isopropanol. Each cage contained 10 bees, and there were 5 cages for each treatment. Control and treatment cages were kept in separate incubators at $33{ }^{\circ} \mathrm{C}$. Every day, the number of live bees remaining was counted. The experiment with $32 \mathrm{mM} \mathrm{3c}\{3,6\}$ in syrup was run for 8 days, and the experiment with $1.0 \mathrm{mM} 3 \mathbf{c}\{3,6\}$ in syrup was run for 14 days.

\section{RESULTS AND DISCUSSION}

The selection of a host by non-reproductive, adult varroa mites depends upon the myriad of chemical signals from honey bees and the hive environment (reviewed by Plettner et al. 2017). Therefore, chemosensing is a worthy target for the development of new varroa control agents. These agents need to act specifically on the varroa mite's olfactory system by blocking or disrupting its host recognition without impairing sophisticated chemical network of the honey bee colony.

\subsection{Electrophysiological response of $3 \mathrm{c}\{3,6\}$ on the varroa and bee olfactory systems}

The present study used chemoecological tools, such as electrophysiological and behavioral assay techniques, to evaluate the effect of $\mathbf{3 c}\{3,6\}$ on the olfactory systems of varroa mites and bees. The electrophysiological recordings showed a positive dose response to $3 \mathbf{c}\{3,6\}$ by bee antennae, but not by varroa forelegs. The response threshold for bee antennae was $0.1 \mu \mathrm{g}$ (Figure 1). The response of the Varroa foreleg to this compound was not significantly different from the solvent control and did not show any dosedependent increase. These results are similar to previously recorded responses of the Varroa and bee olfactory machinery to DEET (Singh et al. 2015). These observations suggest that the olfactory system of the bee must contain olfactory neurons (ORNs) responsive to both DEET and $3 \mathbf{c}\{3,6\}$, but the Varroa foreleg likely does not.

Our previous experience with DEET indicated that compound $3 \mathbf{c}\{3,6\}$ may have a chemosensory disruptive effect on the varroa mite's host detection, even if no direct sensing was observed (Singh et al. 2015). We thus tested the effect of $3 \mathbf{c}\{3,6\}$, on the sensing ability of the varroa foreleg and the bee antenna, by evaluating its effect in combination with the positive stimulus ( 5 nurse bees). Two types of effects were evaluated, which are as follows: long-term inhibition and short-term inhibition. Similarly to Plettner and Gries (2010), Eliash et al. (2014) stated that the short-term inhibition of a positive stimulus is the electrophysiological response when an inhibitory compound is administrated together with the positive stimulus (bee headspace volatiles, in this case), and the mixed stimulus elicits a smaller depolarization than the positive stimulus by itself. 


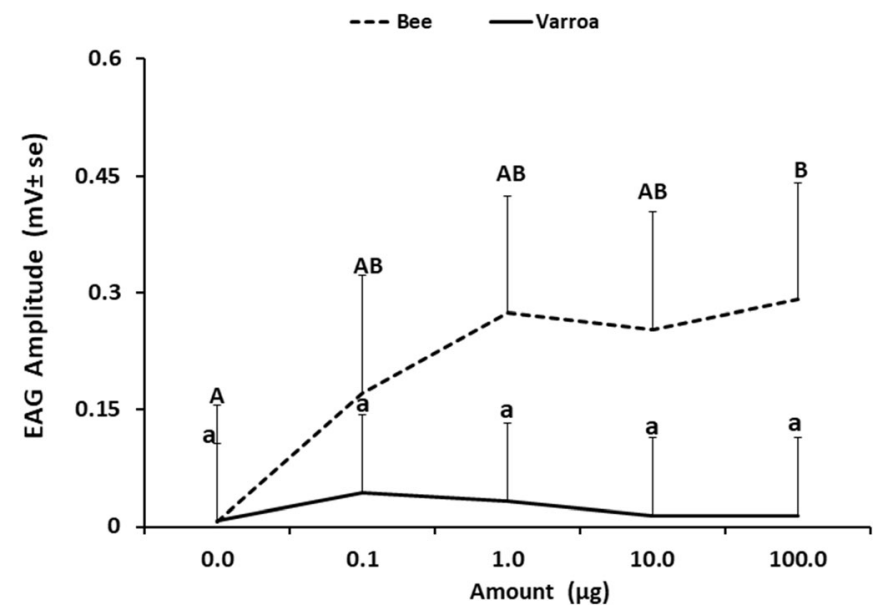

Figure 1. Dose response of $\mathbf{3 c}\{3,6\}$ on Varroa forelegs (solid line) and bee antennae (broken line). Points represent the average responses of 6 Varroa forelegs and 6 bee antennae to stimulation with different amounts of compound $3 \mathbf{c}\{3,6\}$. Data represent the maximal depth $(\mathrm{mV})$ of depolarization of the chemosensory organ upon stimulation. Points are the average + S. D. Different letters (lower case for Varroa and upper case for honey bee) indicate significant differences in responses to ascending amounts. Anova repeated measures $p<0.05$, with Bonferroni correction.

Long-term inhibition is detected when the positive stimulus is given after the mixed stimulus of inhibitory compound plus positive stimulus, and it consists of a decreased response of the second positive stimulus, relative to the one given before the mixed inhibitor stimulus. The results (Figure 2) clearly show that compound $\mathbf{3 c}\{3,6\}$ causes significant inhibition, both short- and long-term, of the varroa foreleg's ability to respond to honey bee headspace. This indicates that response to

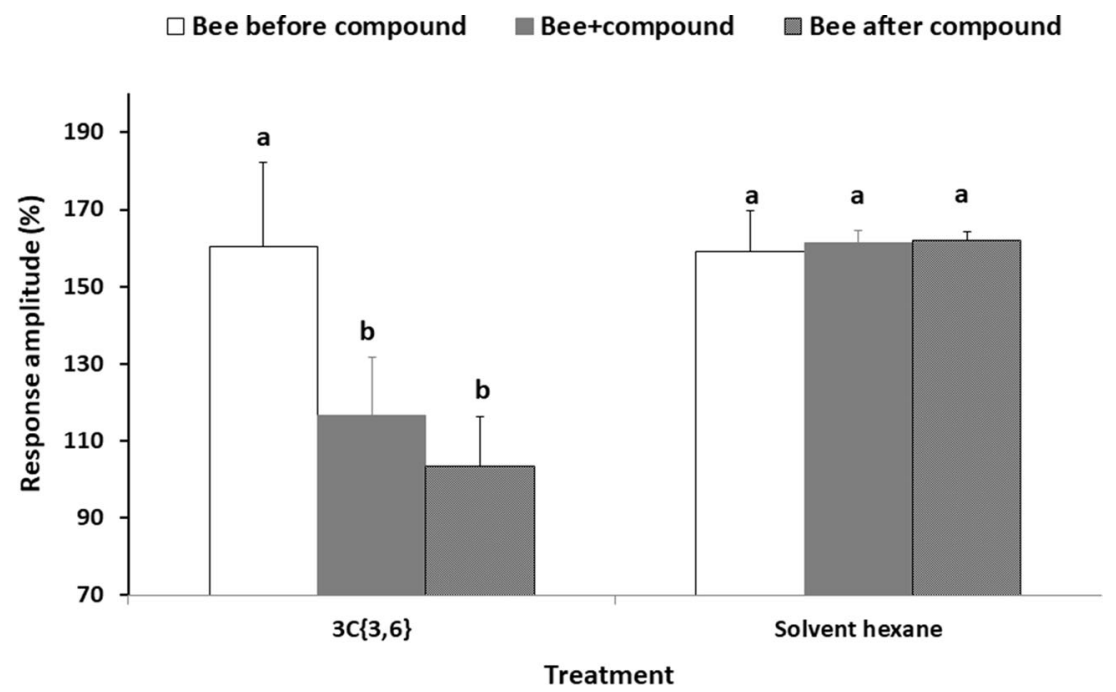

Figure 2. Electrophysiological effect of $3 \mathbf{c}\{3,6\}$ (treatment) or solvent hexane (control) in the presence of bee head space on the Varroa foreleg. Each organ was tested with three sequential stimuli: positive stimulus (5 nurse bees), positive stimulus + compound/solvent, and positive stimulus. Time intervals between stimuli were in the order of $1 \mathrm{~min}$. The results are average normalized values (\%, average + S.E.). Columns marked with different letters are significantly different (Anova repeated measures, followed by a post hoc Tukey-Kramer test, $p<0.05$ ). 


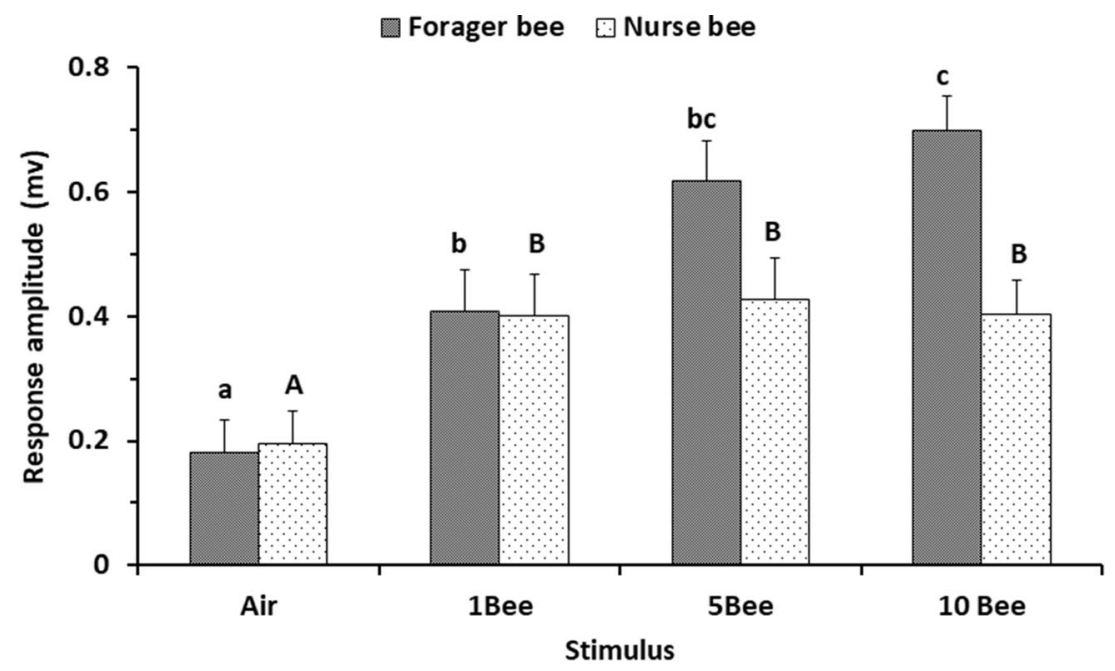

Figure 3. Honey bee electrophysiological responses to bee odors. Bars represent the average response amplitude + S. E. Comparison between the responses to the headspaces of different numbers of nurse or forager bees: no bee (empty bar), 1, 5, and 10 bees. Bars marked with different letters are significantly different, ANOVA repeated measures, $p<0.05, n=6$. Only foragers whose pollen loads had been removed were used as a stimulus source.

3c $\{3,6\}$ is somewhat stronger than to DEET itself which caused only long-term inhibition on the varroa foreleg (Singh et al. 2015). We can hypothesize that the compounds $3 \mathbf{c}\{3,6\}$ and DEET either do not act directly on the Varroa receptors for honey bee odor but interfere somewhere else during the reception process in the olfactory organ or interact with receptors in an antagonistic manner.

To test the specificity of the effect of $\mathbf{3 c}\{3,6\}$ on honey bee chemosensing, we used the same positive stimulus as used in the electrophysiological assay with varroa and tested it specifically on the antennae of nurse bees, as those bees are the

$\square$ Bee before compound $\square$ Bee+compound $\square$ Bee after compound

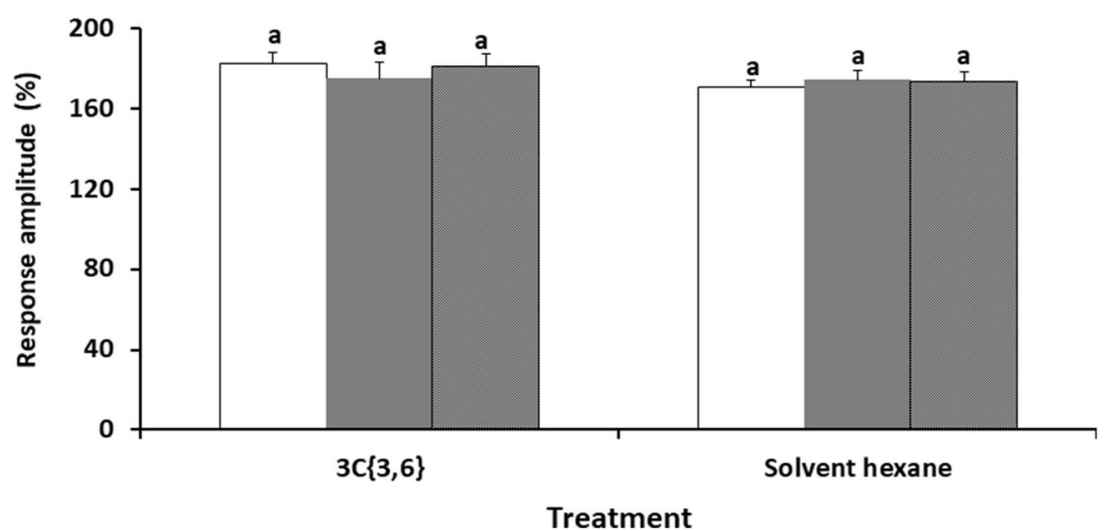

Figure 4. Electrophysiological effect of compound $3 \mathbf{c}\{3,6\}$ or solvent hexane in the presence of bee head space on the bee antenna. Each organ was tested using three sequential stimuli: positive stimulus ( 5 nurse bees), positive stimulus + compound/solvent, and positive stimulus. The results are normalized values (\%, average + S.E.). Columns marked with different letters are significantly different (Anova repeated measures, followed by a post hoc Tukey-Kramer test, $p<0.05$ ). 
major carrier of varroa mites in the bee colony. As a first step, we confirmed the response of nurse antennae to honey bee headspace. The results clearly show that there is a significant response to the bee headspace, as compared with the control (Figure 3). The maximal response was reached at a dose of the head space of one bee. Forager bee head space elicited somewhat stronger responses than nurse headspace. In both cases, headspace of five bees gave a significant and stable response. We thus used the head space from 5 nurse bees as a positive stimulus, to test the effect of compound $3 \mathbf{c}\{3,6\}$ on nurse bee antennae. No effect of compound $\mathbf{3 c}\{3,6\}$ was found on the response of bee antennae to nurse volatiles (Figure 4). The reason behind the differences between the electrophysiological effect in varroa and the honey bee is still unknown. The most likely reason is that the building blocks of the molecular olfactory mechanism of mites (Acari) and bees (insects) are not alike. For example, the odorant receptor-co-receptor, OR-ORCO, complex is unknown in non-insect arthropods, so only the honey bee will have this and not the mites (Missbach et al. 2014). Moreover, recently we have found some putative chemosensory transcripts in the varroa that are significantly different from those of the honeybee (Eliash et al. 2017, 2019).

In our previous structure-activity studies with varroa mites, we found that other para-substituted dialkoxybenzenes, namely, 1,4diethoxybenzene, 1-methoxy-4-propoxybenzene, and 1-ethoxy-4-propoxybenzene were not active with regard to the modulation of electrophysiological signals elicited by honey bee head space volatiles, and 1,4-diethoxybenzene was not active with regard to the alteration of host choice (Eliash et al. 2014). In contrast, the ortho - and meta-
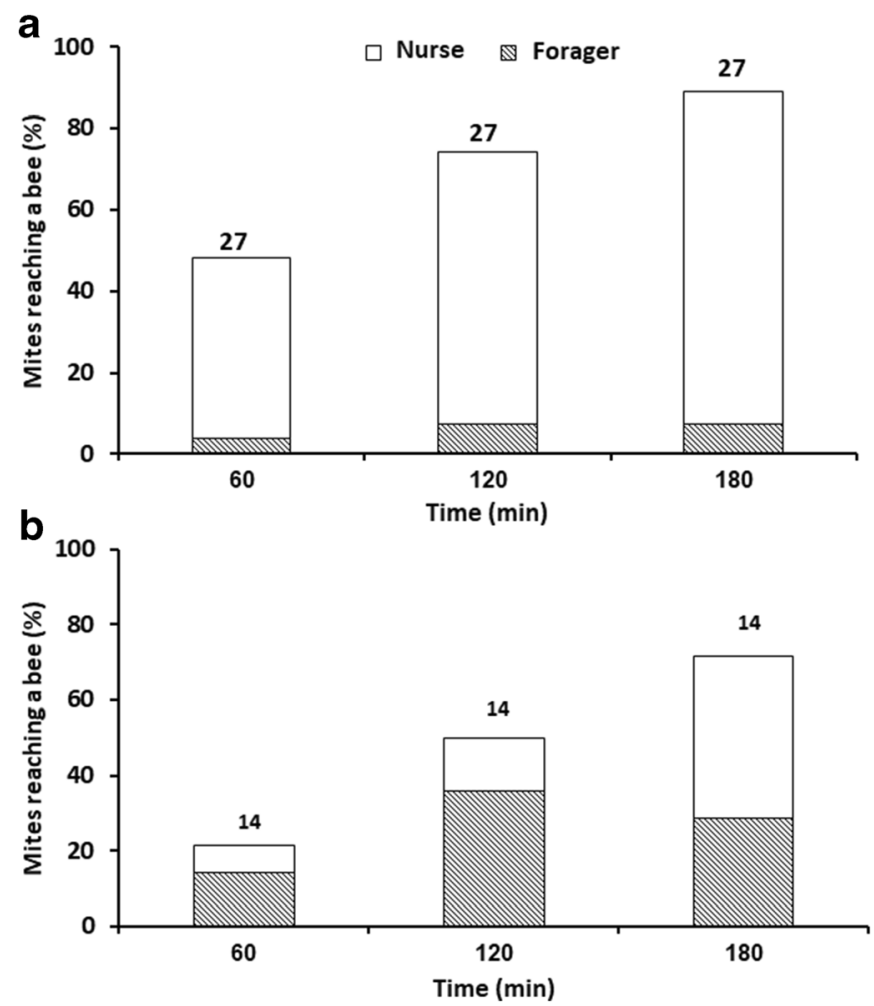

Figure 5. The effect of hexane control or $3 \mathbf{c}\{3,6\}$ treatment on the choice of varroa mites between nurse and forager bees. Bars represent the percentage of mites selecting a nurse (white) or a forager (stippled) after 60, 120, and $180 \mathrm{~min}$ out of the total number of mites that remained alive, after $180 \mathrm{~min}$, namely, 27 and 14 for control and treatment, respectively. The total number of mites in each treatment group was 30. (a) Control: hexane $(1 \mu \mathrm{L})$ on parafilm. (b) Treatment with compound $3 \mathbf{c}\{3,6\}$ at $10 \mu \mathrm{g}$ in $1 \mu \mathrm{L}$ hexane on parafilm. 
substituted diethoxybenzenes were active electrophysiologically as long-term inhibitors of electrophysiological Varroa foreleg responses to honey bee head space (Eliash et al. 2014). Additionally, 1,3-diethoxybenzene was among the most active compounds we found that alter the host choice of Varroa. Here, we have found that 1-allyloxy-4propoxybenzene is active in terms of long-term inhibition of the varroa foreleg responses to honey bee head space and in terms of host choice interaction.

\subsection{Behavioral effects of $3 \mathbf{c}\{3,6\}$ on varroa mites and honey bees}

As the impact of the electrophysiologically active compounds on behavior is unpredictable, we tested the effect of $\mathbf{3} \mathbf{c}\{3,6\}$ on a mite's host choice between a nurse and a forager bee. The results clearly showed (Figure 5) that in the control group varroa mites started moving shortly after the experiment and approximately $80 \%$ of the mites reached any of the hosts at the end of a three-hour experiment. Most of the mites (81\%) preferred a nurse bee (goodness of fit, $p<0.05$ ), as expected according to many previous reports (Kraus 1993; Eliash et al. 2014; Singh et al. 2015). However, in the presence of $\mathbf{3 c}\{3,6\}$, the movement of the mites towards any of the bees was very slow (Figure 5) and by the end of the experiment the selection of any of the hosts was significantly reduced as compared with the control (goodness of fit, $p<0.05$ ). Only $45 \%$ of mites reached any host. This reduced host selection was similar to previously observed in response to DEET. Observation of the mites exposed to
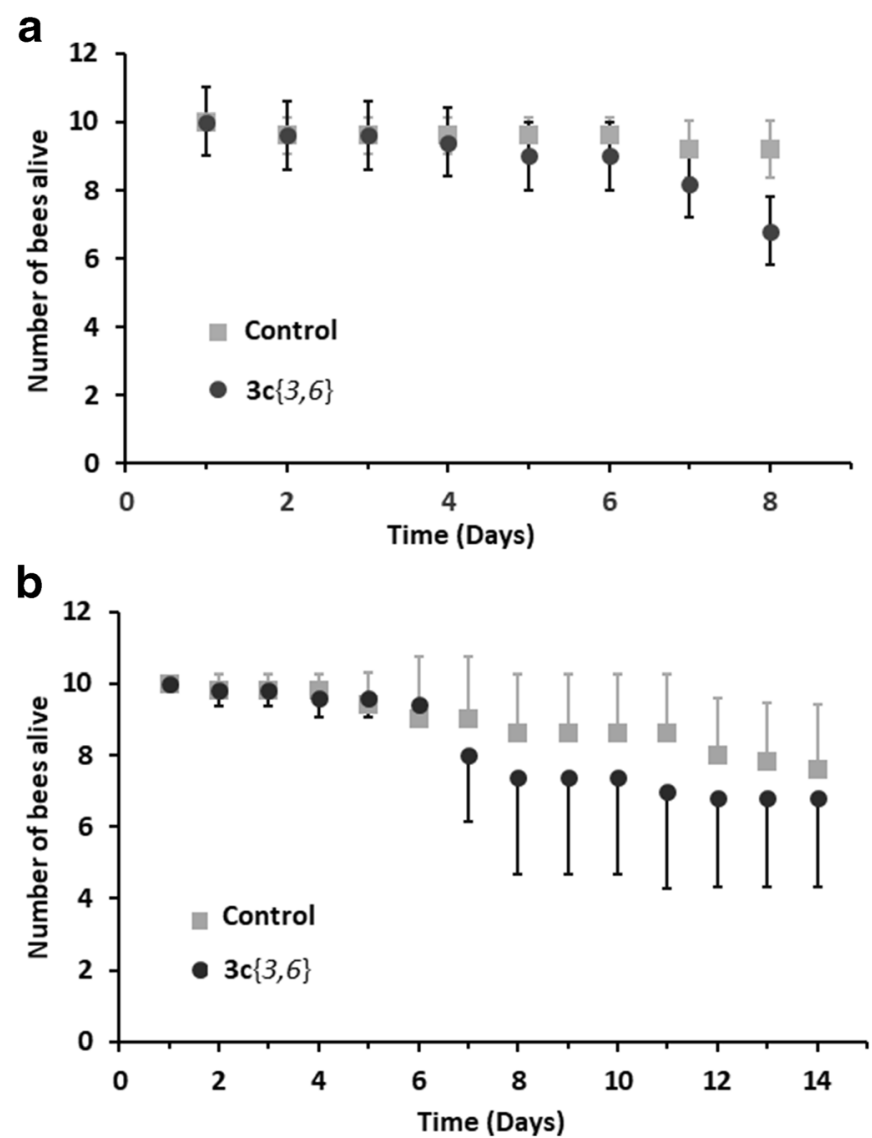

Figure 6. Effect of compound $\mathbf{3 c}\{3,6\}$ on bee survival when fed in sugar syrup, at $32 \mathrm{mM}$ (a) or $1.0 \mathrm{mM}$ (b). Points represent the mean \pm S.D. of 5 replicates with 10 bees each at the beginning. In both cases, treatments and controls did not differ significantly $(t$ test, $p>0.05)$. 
$3 \mathbf{c}\{3,6\}$ revealed that they became paralyzed and $53 \%$ eventually died during the experimental time, which explains why less than half of the mites reached any host.

The effect of evaporating compound $\mathbf{3 c}\{3,6\}$ on bee survival was tested in hoarding cages. This is a standard method for screening potentially harmful compounds (Medrzycki et al. 2013). Survival of bees in control and treated groups was similar along the experiment $(21 \%$ and $5 \%$ bees died at the end of experiment after $72 \mathrm{~h}$ in control and treated groups, respectively). In addition, we have also noticed that there were no differences in the general behavior of the honey bees. The effect of compound $\mathbf{3 c}\{3,6\}$ fed to the bees in sugar syrup was also not significant (Figure 6), both at an excessively high concentration $(32 \mathrm{mM})$ and at a lower concentration of $1.0 \mathrm{mM}$.

Previously, the partition (gas/liquid; liquid/liquid) (Ebrahimi et al. 2013) and the biodegradation by Gram-negative bacteria commonly found in the environment were investigated (Ebrahimi and Plettner 2014). Compound 3c $\{3,6\}$ has a $\log \mathrm{K}_{\mathrm{o} / \mathrm{w}}$ (also known as $\log \mathrm{P}$ ) of $2.40 \pm 0.17$ (Ebrahimi et al. 2013). Various strains of commonly found Pseudomonas putida, particularly the one with cytochrome P450 cam (CYP101A1) have been shown to biodegrade the compound by initial dealkylation (Ebrahimi and Plettner 2014).

Taken together, the results presented here support a chemosensory approach as part of an integrated control of this major apiculture pest. The data suggest that compound $\mathbf{3 c}\{3,6\}$ with its specific behavioral effects is a good candidate for further evaluation. In particular, its efficacy and safety to bees still remain to be tested on a colony level.

\section{ACKNOWLEDGMENTS}

This project was supported by the Jewish Charitable Association, grant no 131-1740, and subsequently by grant from the Chief Ministry of Agriculture grant no. 131-1815, as well as grants from the Natural Sciences and Engineering Research Council (NSERC) of Canada \# STGP/396484-2010 and STGP/494068-16. We thank Dr. Linda Cameron for assistance with the synthesis of 3c $\{3,6\}$ and Yosef Kamer for assistance with beekeeping.

\section{AUTHOR CONTRIBUTIONS}

NKS, NE, and SR did the assays with mites and mite electrophysiology. JK did the toxicological tests, YY synthesized the compound, and EP and VS designed the experiments. All the authors helped with writing and discussion.

Effet du 1-allyloxy-4-propoxybenzène, un inhibiteur de l'alimentation des insectes sur les réponses olfactives et le choix de l'hôte de Varroa destructor.

chimioréception des invertébrés / détection de l'hôte / olfaction / dialcoxybenzène / choix de l'hôte.

Der Effekt von 1-Allyloxi-4-Propoxibenzen, ein Inhibitor der Futteraufnahme bei Insekten, auf die olfaktorische Antwort und Wirtswahl bei Varroa destructor.

Chemorezeption bei Invertebraten / Wirtserkennung / Geruchswahrnehmung / Dialkoxibenzen / Wirtswahl.

\section{REFERENCES}

Akhtar Y., Yu Y., Isman M.B., Plettner E. (2010) Dialkoxybenzene and dialkoxyallybenzene feeding and oviposition deterrents against the cabbage looper, Trichoplusia $n i$ : potential insect behaviour control agents. J. Agric. Food Chem. 58: 4983-4991.

Berry J. A., Hood W. M., Pietravalle S., Delaplane K. S. (2013) Field-level sublethal effects of approved bee hive chemicals on honey bees (Apis mellifera L). PLoS ONE 8(10): e76536.

Cabrera A. R., Shirk P. D., Teal P. E. A. (2017) A feeding protocol for delivery of agents to assess development in Varroa mites. PLoS ONE 12(4): e0176097.

Cameron L. M., Rogers M., Aalhus M., Seward B., Yu Y., Plettner E. (2014) Feeding deterrence of cabbage looper (Trichoplusia ni) (Lepidoptera: Noctuidae) by 1allyloxy-4-propoxybenzene, alone and blended with neem extract. J. Econ. Entomol. 107: 2119-2129.

Corbel V., Stankiewicz M., Pennetier C., Fournier D., Stojan J., Girard E., Dimitrov M., Molgó J., Hougard J.M., Lapied B. (2009) Evidence for inhibition of cholinesterases in insect and mammalian nervous systems by the insect repellent deet. BMC Biol 47: 1-11.

Ebrahimi P., Plettner E.. (2014) Biodegradation of 1allyloxy- 4-propoxybenzene by selected strains of Pseudomonas putida. Biodegradation 25: 31-39. 
Ebrahimi P., Spooner J., Weinberg N., Plettner E. (2013) Partition, sorption and structure activity relation study of dialkoxybenzenes that modulate insect behavior. Chemosphere 93: 54-60.

Eliash N. (2012) Learning and Disrupting the Chemical Communication of Varroa destructor Anderson and Trueman. Jerusalem: Hebrew University.

Eliash N., Singh N.K., Kamer Y., Pinnelli G.R., Plettner E., Soroker V.(2014) Can we disrupt the sensing of honey bees by the bee parasite Varroa destructor? PLoS One 9(9): e106889.

Eliash N., Singh N.K., Thangarajan S., Sela N., Leshkowitz D., Zaidman I., Kamer Y., Rafaeli A., and Soroker, V. (2017) Chemosensing of honeybee parasite, Varroa destructor: transcriptomic analysis. Scientific Reports 7: 13091 .

Eliash N., Thangarajans S., Sela N., D., Zaidman I., Kamer Y., Rafaeli A., and Soroker V. (2019) Varroa chemosensory proteins: some are conserved across Arthropoda but others are arachnid specific. Insect Mol. Biol. 28:321-341.

Francis R. M., Nielsen S. L., Kryger P. (2013) Varroa-virus interaction in collapsing honey bee colonies. PLoS ONE 8(3): 357540.

Frost E. H., Shutler D., Hillier N. K. (2013) Effects of fluvalinate on honey bee learning, memory, responsiveness to sucrose, and survival. J. Exp. Biol. 216: 2931-2938.

González-Cabrera J., Davies T.G.E., Field L.M., Kennedy P.J., Williamson M.S. (2013) An amino acid substitution (L925V) associated wtih resistance to pyrethroids in Varroa destructor. PLoS One 8(12): e82941.

Hillier N. K., Frost E. H., Shutler D. (2013) Fate of dermally applied miticides fluvalinate and amitraz within honey bee (Hymenoptera: Apidae) bodies. J. Econ. Entomol. 106: 558-565.

Hodson C. N., Yu Y., Plettner E., Roitberg B. D. (2016) New repellent effective against Anopheles gambiae: implications for malaria vector control. Med. \& Vet. Entomol. 30: 369-376.

Kraus B. (1993) Preferences of Varroa jacobsoni for honey bees (Apis mellifera L.) of different ages. J. Apic. Res. 32: 57-64.

Kuster R. D., Boncristiani H. F., Rueppell O. (2014) Immunogene and viral transcript dynamics during parasitic Varroa destructor mite infection of developing honey bee (Apis mellifera) pupae. J. Exp. Biol. 217: 1710-1718.

Martin S.J. (2004). Acaricide (pyrethroid) resistance in Varroa destructor. Bee World, 85: 67-69.

Medrzycki P., Giffard H., Aupinel P., Belzunces L.P., Chauzat M-P, et al. (2013) Standard Methods for Toxicology Research in Apis mellifera. in V Dietemann;
JD Ellis; P Neumann (Eds) The Coloss Beebook, Volume I: Standard Methods for Apis mellifera Research. J. Apic. Res., 52, DOI https://doi.org/10.3896 /IBRA.1.52.4.14

Missbach C., Dweck H.K., Vogel H., Vilcinskae A., Stensmyr M.C., Hansson B.S., Grosse-Wilde E. (2014). Evolution of insect olfactory receptors. Elife 3: $1-22$.

Mondet F., Goodwin M., Mercer A. (2011) Age-related changes in the behavioral response of honey bees to Apiguard $₫$, a thymol-based treatment used to control the mite Varroa destructor. J. Comp. Physiol. A, 197: 1055-1062.

Nazzi, F., Le Conte, Y. (2015) . Ecology of Varroa destructor, the major ectoparasite of the western Honey Bee, Apis mellifera, Ann. Rev. Entomol. 61: 417-432.

Nazzi F., Milani N., Vedova G.D., Nimis M. (2001) Semiochemicals from larval food affect the locomotory behaviour of Varroa destructor. Apidologie 32: 149155.

Paduraru P.M., Popoff R.T., Nair R., Gries R., Gries G., et al. (2008) Synthesis of substituted alkoxy benzene minilibraries, for the discovery of new insect olfaction or gustation inhibitors. J. Comb. Chem. 10: 123-134.

Pernal S.F., Baird D.S., Birmingham A.L., Higo H.A., Slessor K.N., et al. (2005) Semiochemicals influencing the host-finding behaviour of Varroa destructor. Exp. Appl. Acarol. 37: 1-26.

Plettner E., Gries R. (2010). Agonists and antagonists of antennal responses of gypsy moth (Lymantria dispar) to the pheromone (+)-disparlure and other odorants. J. Agric. and Food Chem. 58: 3708-3719.

Plettner E., Eliash N., Kumar N. S., Pinnelli G. R., Soroker V. (2017) The Chemical Ecology of Host-Parasite Interaction as a Target of Varroa destructor Control Agents. Apidologie. 48: 78-92.

Ramsey S., Ochoa R., Bauchan B., Gulbronson C., Mowery J. D., et al. (2019) Varroa destructor feeds primarily on honey bee fat body tissue and not hemolymph. Proc. Natl. Acad. Sci. 116: 1792-1801.

Rosenkranz P., Aumeier P., Ziegelmann B. (2010). Biology and control of Varroa destructor, J. Invert. Pathol. 103: S96-S119.

Singh N.K., Eliash N., Kamer Y., Zaidman I., Plettner E., Soroker V. (2015). The effect of DEET on chemosensing of the honey bee and its parasite Varroa destructor, Apidologie 46: 380-391.

Publisher's note Springer Nature remains neutral with regard to jurisdictional claims in published maps and institutional affiliations. 